Tropical Journal of Pharmaceutical Research September 2021; 20 (9): 1909-1914

ISSN: $1596-5996$ (print); 1596-9827 (electronic)

(C) Pharmacotherapy Group, Faculty of Pharmacy, University of Benin, Benin City, 300001 Nigeria.

Original Research Article

http://dx.doi.org/10.4314/tjpr.v20i9.18

\title{
Oxytocin protects neurons from hypoxic-ischemic brain injury by enhancing inhibitory neurotransmission in neonatal rats
}

\author{
Linhua Xiang, Rong Wu, Kangling Liu, Jing Wang* \\ Department of Pediatrics, Wuhan Fifth Hospital, Wuhan 430050, Hubei Province, China
}

*For correspondence: Email: spxfg4@163.com

Sent for review: 31 May 2021

Revised accepted: 16 August 2021

\begin{abstract}
Purpose: To study the protective effect of oxytocin on hypoxic-ischemic brain neuron injury in neonatal rats, and the mechanism of action involved.

Methods: Hippocampal slices from neonatal SD rats were cultured in oxygen/glucose-deprived (OGD) solution, leading to establishment of hypoxic-ischemic model of hippocampal slices in vitro. The slices were assigned to 3 groups: control (ACSF solution), model (OGD solution), and oxytocin (OGD solution $+1 \mu M$ oxytocin). The effect of oxytocin on vertebral neurons in hippocampal CA1 region of HIBD rats was determined using TOPRO-3 staining, while the effects of oxytocin on hypoxic depolarization (AD) and inhibitory postsynaptic currents (iPSCs) were measured by cell patch clamp technique.

Results: The fluorescence intensity of vertebral lamina in hippocampal CA1 area of model group was significantly higher than that of control group, while the corresponding value for oxytocin group was significantly lower than that of model group $(p<0.05)$. The time lapse before occurrence of $A D$ in hippocampal CA1 area was significantly longer in oxytocin group than in model group, while the time lapse before neuronal $A D$ in oxytocin receptor antagonist group was lower than that in oxytocin group. The frequency and amplitude of iPSCs in oxytocin group were markedly higher than the corresponding control values.

Conclusion: Oxytocin exerts protective effect against hypoxic-ischemic brain neuronal damage in neonatal rats by regulating the activation of oxytocin receptor and GABA receptor, and inhibiting nerve transmission. These findings may be of benefit in the development of a suitable therapy for HIBD.
\end{abstract}

Keywords: Oxytocin receptor, Neurotransmission; Hypoxic-ischemic brain neuron damage, Vertebral lamina, Hippocampal

\begin{abstract}
This is an Open Access article that uses a funding model which does not charge readers or their institutions for access and distributed under the terms of the Creative Commons Attribution License (http://creativecommons.org/licenses/by/4.0) and the Budapest Open Access Initiative (http://www.budapestopenaccessinitiative.org/read), which permit unrestricted use, distribution, and reproduction in any medium, provided the original work is properly credited.
\end{abstract}

Tropical Journal of Pharmaceutical Research is indexed by Science Citation Index (SciSearch), Scopus, International Pharmaceutical Abstract, Chemical Abstracts, Embase, Index Copernicus, EBSCO, African Index Medicus, JournalSeek, Journal Citation Reports/Science Edition, Directory of Open Access Journals (DOAJ), African Journal Online, Bioline International, Open-J-Gate and Pharmacy Abstracts

\section{INTRODUCTION}

Neonatal hypoxic-ischemic brain damage (HIBD) is a severe childhood disability caused by cerebral ischemia and hypoxia during perinatal asphyxia. It manifests mainly in changes in the state of consciousness and muscle tone, and it causes a series of complications such as intellectual retardation and cerebral palsy. Indeed, HIBD has become one of the main causes of neonatal acute death and chronic nervous system injury, resulting in huge 
economic burden and heavy mental pressure on the affected families and society [1]. Therefore, there is need for in-depth studies on the pathogenesis of HIBD so as to develop newer and more effective treatment methods for the disease.

At present, many researchers believe that multiple mechanisms such as oxidative stress, inflammation and excitatory toxicity are jointly involved in the pathogenesis of HIBD. Excitatory toxicity is closely related to neurotransmitters in the brain, with gamma aminobutyric acid (GABA) as the main neurotransmitter. Signal enhancement is one of the protective mechanisms involved in neuronal ischemia and hypoxia injury. Thus, drugs that enhance GABA signal are expected to be new drugs for the treatment of HIBD $[2,3]$. The hippocampus is the site most commonly involved in HIBD. Ischemia and hypoxia easily lead to disorders in synaptic transmission in hippocampal neurons, indicating that reducing neuronal damage in the hippocampus may be a promising and new target in the treatment of HIBD [4].

Oxytocin, a physiological hormone produced by the paraventricular nucleus and supraoptic nucleus of the hypothalamus and released in the posterior pituitary gland, has been used in clinical practice for long, due to its potential to induce labor and stimulate milk secretion [5]. Studies have shown that oxytocin produced therapeutic effects on a variety of nervous system diseases. For example, it significantly enhanced inhibitory neurotransmission in hippocampal neurons of young mice [6]. The purpose of this study was to determine the protective effect of oxytocin against hypoxic-ischemic brain neuronal injury in neonatal rats, and to further study the mechanism involved.

\section{EXPERIMENTAL}

\section{Reagents and equipment}

The reagents and instruments used in this study, and their sources (in brackets) were: DVOT (Shanghai Yubo Biotechnology Co. Ltd); TOPRO-3 reagent (American Yingjie Life Technology Co., Ltd); sodium bicarbonate (Shanghai Fanwei Biotechnology Co. Ltd.); tetraethylamine (Shanghai Yaji Biotechnology Co. Ltd); potassium gluconate (Shanghai Baoman Biotechnology Co. Ltd); agar (Beijing Yita Biotechnology Co. Ltd) and hydrochloric acid standard solution (Beijing Yita Biological Technology Co. Ltd). The instruments were: fluorescence microscope (Guangzhou Keste Scientific Instrument Co. Ltd); glass microelectrode (Shanghai Yuyan Scientific Instrument Co. Ltd); microscope X-Y mobile table (Taibok Electric Co. Ltd); vibrating slicing machine (Beijing Bianji Technology Co. Ltd); low negative pressure aspirator (Guangzhou Beamat Instrument Equipment Co. Ltd); electronic constant temperature stainless steel water bath (Tianjin Aunuo Instrument Co. Ltd); vortex oscillator (Shanghai Fuze Trading Co. Ltd); microcentrifuge (Shanghai Jingxin Industrial Development Co. Ltd); magnetic stirrer (Shanghai Fuze Trading Co. Ltd); refrigerated centrifuge (Wuhan Kehaojia Biotechnology Co. Ltd), and confocal microscope (Beijing Anmag Trading Co. Ltd).

\section{Animals and grouping}

Sprague-Dawley (SD) rats were provided by Beijing Vitong Lihua Experimental Animal Technology Co. Ltd. The rats were raised in the Animal Experimental Center of Wuhan Fifth Hospital at temperatures of $24-26{ }^{\circ} \mathrm{C}$ in a $12-\mathrm{h}$ light /12-h dark environment, with ad libitum access to feed and drinking water. Neonatal rats aged 7 - 10 days were selected for the experiment. The study received approval from the Animal Ethical Committee of Wuhan Fifth Hospital (approval no. WFH20190382), and was conducted in line with "Principles of Laboratory Animal Care" [7].

\section{Topro-3 staining}

Topro-3 staining solution was prepared with ACSF solution at a volume ratio of 1:2000. After the brain slices were immersed in Krebs solution for $1 \mathrm{~h}$, they were incubated for $20 \mathrm{~min}$, and then placed in the Topro-3 staining solution for 20 min. Thereafter, the slices were soaked in Krebs solution for $10 \mathrm{~min}$ to wash away residual dye solution. The brain slices were examined under laser confocal microscopy at excitation wavelength of $639 \mathrm{~nm}$. Slices $20 \mu \mathrm{m}$ away from the surface were photographed with the same parameters. The fluorescence intensity of CA1 area in each section was calculated.

\section{Whole cell patch clamp technique}

The time taken for occurrence of $A D$ was recorded in the current clamp mode. The neuronal membrane potential rose rapidly to 0 $m V$ for $A D$, and the time of occurrence was the period from the start of oxygen-glucose deprivation, through the occurrence of rapid neuronal depolarization, to the end point. The frequency and amplitude of inhibitory postsynaptic current (IPSCs) were recorded formally 
and continuously after the cell recording became stable.

\section{Statistics}

Measurement data consistent with normal distribution are presented as mean \pm SD. Twogroup comparison was done with $t$-test, while multiple-group comparison was carried out with one-way ANOVA. The SPSS version 21.0 was used for statistical analyses. Statistical significance was assumed at $p<0.05$.

\section{RESULTS}

\section{Effect of oxytocin on vertebral layer neurons in hippocampal CA1 regions of HIBD rats}

Slices of brain tissues from 8 neonatal rats were randomly divided into control group (incubated with normal ACSF fluid), model group (in vitro hypoxic-ischemia model of hippocampal slices incubated with OGD solution), and oxytocin group (OGD solution incubated with $1 \mu \mathrm{M}$ oxytocin).

Effect of oxytocin on anoxic depolarization (AD) of vertebral neurons in the hippocampal CA1 region of rats

Twenty neonatal rats were randomly divided into 4 groups, with 5 groups in each group: model group (incubated with OGD), oxytocin group (incubated with OGD $+1 \mu \mathrm{M}$ oxytocin), oxytocin receptor antagonist group (OGD incubation + 1 $\mu \mathrm{M}$ oxytocin + $1 \mu \mathrm{M}$ DVOT), and GABA receptor antagonist group (incubated with $+1 \mu \mathrm{M}$ oxytocin $+10 \mu \mathrm{M}$ bicuculline).

\section{Effect of oxytocin on hippocampal CA1 vertebral layer neurons in HIBD rats}

The results of TOPRO-3 staining showed that the fluorescence intensity of the vertebral layer in the hippocampal CA1 region was markedly higher in model group than in control group, while the fluorescence intensity of vertebral layer in hippocampal CA1 region of rats in oxytocin group was significantly lower than the corresponding model value. These results are presented in Figure 1 and Figure 2.

\section{Effect of oxytocin on $A D$ of vertebral neurons in hippocampal CA1 zone of rats}

Table 1 shows that the time lapse before occurrence of $A D$ in the hippocampal CA1 zone of oxytocin rats was significantly higher than that in the model group $(p<0.01)$, while the times before the occurrence of neuronal $A D$ in the oxytocin receptor antagonist and GABA receptor antagonist group were markedly lower than the corresponding oxytocin values.

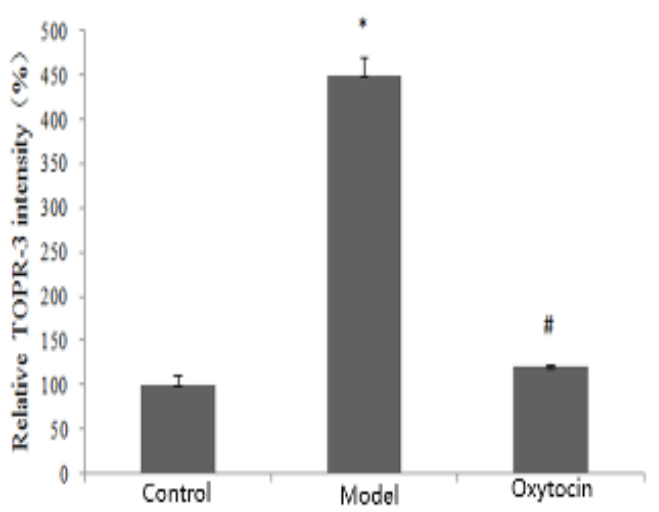

Figure 1: Fluorescence intensity of the vertebral layer in hippocampal CA1 region of rats in each group, as observed via TOPRO-3 staining. ${ }^{*} P<0.05$, vs control; ${ }^{\#} p<0.05$, vs model group
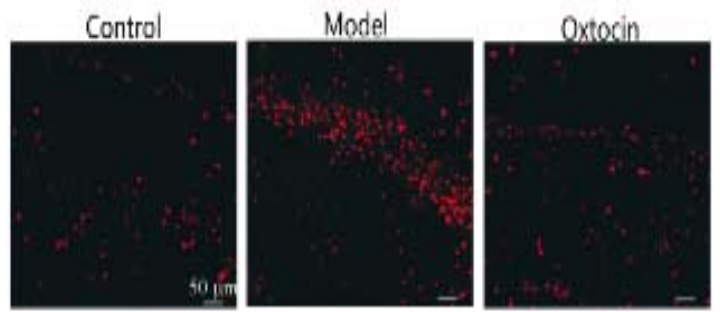

Figure 2: Representative TOPO-3 fluorescence images of the three groups

Table 1: Occurrence time of $A D$ of vertebral neurons in hippocampal CA1 region of rats (mean $\pm S D, n=5$ )

\begin{tabular}{lc}
\hline Group & $\begin{array}{c}\text { AD occurrence time } \\
(\text { min) }\end{array}$ \\
\hline Model & $13.52 \pm 1.78$ \\
Oxytocin & $23.16 \pm 2.02^{*}$ \\
Oxytocin receptor antagonist & $15.62 \pm 1.72 \#$ \\
GABA receptor antagonist & $12.68 \pm 2.52 \#$ \\
$F$ & 27.52 \\
$P$-value & $<0.001$ \\
\hline Data are shown as mean \pm SD. ${ }^{*} P<0.05$, vs control; \\
${ }^{\#} p<0.05$, vs the model group &
\end{tabular}

Effect of oxytocin on IPSCs of vertebral neurons in hippocampal CA1 region of rats

As shown in Table 2, the frequency and amplitude of IPSCs in the hippocampal CA1 zone of rats were markedly higher in oxytocin group than in the control group, but there was no significant difference in IPSCs decay time between the model and control values.

Trop J Pharm Res, September 2021; 20(9): 1911 
Table 2: Effect of oxytocin on IPSCs of vertebral neurons in hippocampal CA1 region of rats

\begin{tabular}{lccc}
\hline Group & $\begin{array}{c}\text { Frequency } \\
(\mathbf{H z})\end{array}$ & $\begin{array}{c}\text { Amplitude } \\
(\mathbf{p A})\end{array}$ & $\begin{array}{c}\text { Decay time } \\
(\mathbf{m s})\end{array}$ \\
\hline Model & $0.51 \pm 0.38$ & $17.08 \pm 3.05$ & $21.45 \pm 1.89$ \\
Oxytocin & $3.05 \pm 0.48$ & $20.48 \pm 0.87$ & $19.48 \pm 0.55$ \\
$t$ & 9.277 & 2.397 & 2.249 \\
$P$-value & $<0.001$ & 0.043 & 0.055 \\
\hline \multicolumn{4}{l}{ Values are mean $\pm \mathrm{SD}(\mathrm{n}=5)$}
\end{tabular}

\section{Effect of different doses of oxytocin on IPSCs of vertebral neurons in hippocampal CA1 region of rats}

Oxytocin enhanced IPSCs in the hippocampal CA1 region in a dose-dependent manner, as shown in Table 3

Table 3: Effect of different doses of oxytocin on IPSCs

\begin{tabular}{lcc}
\hline $\begin{array}{l}\text { Oxytocin dose } \\
(\boldsymbol{\mu M})\end{array}$ & $\begin{array}{c}\text { Frequency } \\
(\mathbf{H z})\end{array}$ & $\begin{array}{c}\text { Amplitude } \\
(\mathbf{p A})\end{array}$ \\
\hline 1 & $9.12 \pm 2.05$ & $1.30 \pm 0.12$ \\
0.5 & $9.01 \pm 2.11$ & $1.11 \pm 0.01$ \\
0.1 & $5.89 \pm 1.02$ & $1.21 \pm 0.11$ \\
0.01 & $3.23 \pm 0.48$ & $1.21 \pm 0.12$ \\
0.001 & $1.20 \pm 0.11$ & $1.11 \pm 0.10$ \\
\hline Values are mean \pm SD $(\mathrm{n}=5)$ &
\end{tabular}

\section{Effect of oxytocin antagonist on IPSCs}

The mean frequency of IPSCs was $1.10 \pm 0.12$ times, and the mean amplitude was $1.00 \pm 0.01$ times as high as that in the control group when the oxytocin receptor was blocked with $1 \mu \mathrm{M}$ of oxytocin receptor antagonist. These results are shown in Table 4.

Table 4: Effect of oxytocin on IPSCs via oxytocin receptor

\begin{tabular}{lcc}
\hline Oxytocin dose & $\begin{array}{c}\text { Frequency } \\
(\mathbf{H z})\end{array}$ & $\begin{array}{c}\text { Amplitude } \\
(\mathbf{p A})\end{array}$ \\
\hline Control group & $2.95 \pm 0.33$ & $1.22 \pm 0.26$ \\
Oxytocin receptor & $3.25 \pm 0.15$ & $1.21 \pm 0.16$ \\
antagonist group & & \\
$t$ & 1.851 & 0.073 \\
$P$-value & 0.101 & 0.943 \\
\hline Values are mean $\pm \mathrm{SD}(\mathrm{n}=10)$ &
\end{tabular}

\section{DISCUSSION}

Hypoxic-ischemic brain damage (HIBD) is a serious disease in the neonatal period, with an incidence of up to $26 \%$ in developing countries. About $20 \%$ of the affected neonates die during the perinatal period, while the survivors suffer neurodevelopmental disorders, epilepsy and learning disabilities, all of which seriously endanger the physical and mental health of children [8]. The pathogenesis of HIBD is not yet fully understood, although it is generally believed to be related to calcium overload, disorders in energy metabolism, and oxygen free radicalinduced damage $[9,10]$. Therefore, there is need to understand the mechanism involved in the occurrence and development of HIBD, and to evolve a safe and effective treatment strategy for it.

Oxytocin is a neuropeptide hormone synthesized by large cells in the paraventricular nucleus and supraoptic nucleus of the hypothalamus. It is vital for induction of labor and milk secretion. Oxytocin usually acts through a G-protein-coupled receptor to regulate inflammatory response directly related to atherosclerotic cardiovascular disease; it reduces the content of fat and cytokines, and improves glucose tolerance $[11,12]$. Although oxytocin has not been used in the treatment of heart disease, it has shown positive effects in animal models of atherosclerosis, with prospect for broad clinical applications. In addition, oxytocin can be used as a central neurotransmitter or regulator for learning, memory and maternal behavior. It also acts as a neurotransmitter or regulator in the hippocampus of rats: binding sites have been found in the CA1 region, but the specific mechanism is not fully understood [13]. It has been reported that oxytocin significantly weakened the response of hippocampal neurons to electrical stimulation of sciatic nerve in a dosedependent manner, and also reduced the spontaneous firing frequency of neurons, although there was no obvious dose-dependent relationship in the later effect [14].

The results obtained in the study of the protective effect of oxytocin on hippocampal CA1 neuronal damage in HIBD rats showed that the fluorescence intensity of the vertebral layer in the hippocampal CA1 region of the model group was significantly higher than that of the control group, while the fluorescence intensity of vertebral layer in hippocampal CA1 region in oxytocin group was significantly lower than that in model group. These results suggest that oxytocin can reduce hypoxic-ischemic injury of hippocampal neurons in neonatal rats. Hypoxic depolarization (AD) is one of the early changes in cerebral ischemia. It leads to changes in electrolyte composition within and outside cells, and it is one of the important electrophysiological markers of neuronal death $[15,16]$.

In this study, the effect of oxytocin on time of occurrence of $A D$ was studied. It was found that the time taken for occurrence of $A D$ in the vertebral neurons in hippocampal CA1 region of oxytocin rats was significantly longer than that in 
the model group, but the occurrence times of neuronal $A D$ in oxytocin receptor antagonist and GABA receptor antagonist were significantly lower than those of oxytocin group, suggesting that oxytocin prolonged the $A D$ time of rat hippocampal vertebral neurons. Gamma aminobutyric acid (GABA) is an excitatory neurotransmitter, and its receptor antagonist completely inhibited the effect of oxytocin on the occurrence time of AD. Therefore, this study has demonstrated that the mechanism of action of oxytocin is related to the effects of its receptor and GABA receptor antagonist.

The frequency and amplitude of IPSCs in hippocampal CA1 region of rats in the oxytocin group were significantly higher than those in control group, indicating that oxytocin increased the frequency and amplitude of IPSCs, but did not change the dynamic characteristics of IPSCs. The results showed that the mean frequency of IPSCs was $1.10 \pm 0.12$ times that of the control group, and the mean amplitude was $1.00 \pm 0.01$ times that of the control group. These results suggest that oxytocin could increase the release of GABA by binding to the oxytocin receptor of GABA-mediated neurons. Studies outside China have revealed that in the hippocampal CA1 region of transgenic mice labeled with golden fluorescence, more than $80 \%$ of excitatory neurons expressed oxytocin receptor, while only $19 \%$ of GABA neurons expressed oxytocin receptor [17-19].

\section{CONCLUSION}

Oxytocin exerted significant protective effect against hypoxic ischemic brain neuronal injury in neonatal rats through a mechanism related to the regulation of oxytocin receptor and GABA receptor activation, thereby inhibiting neurotransmission. These findings may be beneficial in the clinical treatment of HIBD.

\section{DECLARATIONS}

\section{Conflict of interest}

No conflict of interest is associated with this work.

\section{Contribution of authors}

We declare that this work was performed by the authors named in this article and all liabilities pertaining to claims relating to the content of this article will be borne by the authors. Jing Wang designed the study, supervised the data collection, and analyzed the data. Linhua Xiang,
Rong Wu and Kangling Liu interpreted the data and prepared the manuscript for publication. Jing Wang supervised the data collection, analyzed the date and reviewed the draft of the manuscript. Linhua Xiang, Rong $\mathrm{Wu}$ and Kangling Liu contributed equally to this work as co-first authors.

\section{Open Access}

This is an Open Access article that uses a funding model which does not charge readers or their institutions for access and distributed under the terms of the Creative Commons Attribution License (http://creativecommons.org/licenses/by/ 4.0) and the Budapest Open Access Initiative (http://www.budapestopenaccessinitiative.org/rea d), which permit unrestricted use, distribution, and reproduction in any medium, provided the original work is properly credited.

\section{REFERENCES}

1. Thomas N, Abiramalatha $T$, Bhat $V$, Varanattu $M$, Rao $S$, Wazir S, Lewis L, Balakrishnan U, Murki S, Mittal J, et al. Phase Changing Material for Therapeutic Hypothermia in Neonates with Hypoxic Ischemic Encephalopathy - A Multi-centric Study. Indian Pediatr 2018; 55(3): 201-205.

2. Lemmon ME, Wagner MW, Bosemani $T$, Carson KA, Northington FJ, Huisman TAGM, Poretti A. Diffusion Tensor Imaging Detects Occult Cerebellar Injury in Severe Neonatal Hypoxic-Ischemic Encephalopathy. Dev Neurosci 2017; 39(1-4): 207-214.

3. Hua C, Ju WN, Jin $H$, Sun $X$, Zhao G. Molecular chaperones and hypoxic-ischemic encephalopathy. Neural Regen Res 2017; 12(1): 153-160.

4. Wusthoff CJ, Sullivan J, Glass HC, Shellhaas RA, Abend NS, Chang T, Tsuchida TN. Interrater agreement in the interpretation of neonatal electroencephalography in hypoxic-ischemic encephalopathy. Epilepsia 2017; 58(3): 429-435.

5. Herbeck YE, Gulevich RG, Shepeleva DV, Grinevich VV. Oxytocin: Coevolution of human and domesticated animals. Russ J Genet Appl Res 2017; 7(3): 235-242.

6. Muniraman $H$, Gardner $D$, Skinner J, Paweletz A, Vayalakkad A, Chee $Y H$, Clifford C, Sanka $S$, Venkatesh V, Curley $A$, et al. Biomarkers of hepatic injury and function in neonatal hypoxic ischemic encephalopathy and with therapeutic hypothermia. Eur J Pediatr 2017; 176(10): 1295-1303.

7. World Health Organization. Principles of laboratory animal care. WHO Chron 1985; 39: 51-56.

8. Goeral $K$, Urlesberger B, Giordano V, Kasprian $G$, Wagner M, Schmidt L, Berger A, Klebermass-Schrehof $K$, Olischar M. Prediction of Outcome in Neonates with Hypoxic-Ischemic Encephalopathy II: Role of Amplitude-Integrated Electroencephalography and

Trop J Pharm Res, September 2021; 20(9): 1913 
Cerebral Oxygen Saturation Measured by Near-Infrared Spectroscopy. Neonatol 2017; 112(3): 193-202.

9. Lee BS, Jung E, Lee Y, Chung SH. Hypothermia decreased the expression of heat shock proteins in neonatal rat model of hypoxic ischemic encephalopathy. Cell Stress Chaperones 2017; 22(3): 409-415.

10. Lee JK, Massaro AN, Northington FJ. The search continues: neuroprotection for all neonates with hypoxic-ischemic encephalopathy. J Thorac Dis 2017; 9(10): 3553-3536.

11. Woolley JD, Chuang B, Fussell C, Scherer S, Biagianti B, Fulford $D$, Mathalon $D H$, Vinogradov $S$. Intranasal oxytocin increases facial expressivity, but not ratings of trustworthiness, in patients with schizophrenia and healthy controls. Psychol Med 2017; 47(7): 1311-1322.

12. Ryan PJ, Ross SI, Campos CA, Derkach VA, Palmiter $R D$. Oxytocin-receptor-expressing neurons in the parabrachial nucleus regulate fluid intake. Nat Neurosci 2017; 20(12): 1722-1733.

13. Kim J, Kang SM, Lee HJ, Choi SY, Hong SH. Oxytocin inhibits head and neck squamous cell carcinoma cell migration by early growth response-1 upregulation. Anticancer Drugs 2017; 28(6): 613-622.

14. Seow KM, Chen KH, Wang PH, Lin YH, Hwang $J L$. Carbetocin versus oxytocin for prevention of postpartum hemorrhage in infertile women with twin pregnancy undergoing elective cesarean delivery. Taiwan J Obstet Gynecol 2017; 56(3): 273-275.

15. Betka S, Gould Van Praag C, Paloyelis Y, Bond R, Pfeifer G, Sequeira $H$, Duka T, Critchley $H$. Impact of intranasal oxytocin on interoceptive accuracy in alcohol users: an attentional mechanism? Soc Cogn Affect Neurosci 2018; 13(4): 440-448.

16. Wang $Y$, Yang $Y B$, Na SJ, Liu T, Hang $C H$, Jiang $B H$, You YP. Melatonin Attenuates Early Brain Injury Via Regulating Mir-181a/Tnf-A/Nf-Kb Signaling Pathway Following Subarachnoid Hemorrhage in Rat. Acta Med Mediterr 2020; 36(6): 3377-3383.

17. Mackeen $A D$, Durie DE, Lin M, Huls CK, Qureshey E, Paglia MJ, Sun H, Sciscione A. Foley Plus Oxytocin Compared with Oxytocin for Induction After Membrane Rupture: A Randomized Controlled Trial. Obstet Gynecol 2018; 131(1): 4-11.

18. Chen YF, Han XT, Zheng D, Dong Q, Wu QM. Diagnostic Value of Serum And Peptide, Brain Natriuretic Peptide And Cardiac Troponin in Elderly Patients with Acute Myocardial Infarction. Acta Med Mediterr 2020; 36(5): 3029-3033.

19. Wu Y, Liao GY, Ke HJ, Liu P. Effects of Snake-Derived Phospholipase A2 Inhibitors on Acute Pancreatitis: In vitro and in vivo Characterization. Drug Des Devel Ther 2020; 14: 4765-4774. 